\title{
Management in the Dürrenstein Wilderness Area - How much human intervention can the wilderness tolerate?
}

\author{
Ingrid Kohl \& Reinhard Pekny
}

Keywords: bark beetle, primeval landscape, self-regulation, dead-wood, wildlife \& visitor management, controlling hoofed game

\section{Abstract}

The Dürrenstein Wilderness Area (WA) is the first and only wilderness area in Austria to date that is recognized by the IUCN as a Category I $(a+b)$ area. It is situated in the south-west of Lower Austria, in the district of Scheibbs near the border with the federal province of Styria.

Coordinates: $47^{\circ} 47^{\prime} 18^{\prime \prime} \mathrm{N}$ latitude; 15 $03^{\prime} 18^{\prime \prime}$ E longitude; altitude 685-1878 m The WA is surrounded by the Natura 2000 area Ötscher-Dürrenstein. Currently the total size of the WA is $25 \mathrm{~km}^{2}$. On a global scale, this is one of the smallest wilderness areas of its kind and will remain so, even if substantial expansion is planned for the near future.

For Central Europe, however, the quality of the natural assets and the size must be considered exceptional. One reason for this is the largest remnant of primeval mountain forest in the Alps, the Rothwald. This virgin forest of spruce, fir and beech was the initial cause for creating the WA to protect this natural treasure and to mitigate impacts from outside. Rothwald virgin forest covers nearly 500 hectares on the southern slope of the Dürrenstein and makes up the core of the WA. It is surrounded by near-natural woodland that was last used for timber about 200-250 years ago. Since that time these forests have grown up on clearances without any human intervention.
Profile

Protected area

Dürrenstein Wilderness Area

Mountain range

Alps

Country

Austria

\section{Objectives}

The key task of this protected area is to protect processes, i.e. letting natural processes happen as well as capturing and exploring them. Effective conservation of the remaining primeval landscape is called for. On already used areas, wilderness is allowed to develop again by reducing human input as much as possible and allowing the free play of natural forces.

Despite the relatively short time of only ten years since the Wilderness Area (WA) was established, this approach has brought about encouraging developments towards wilderness. In the former commercial forests, too, massive dynamics have started to work, speeded up by some extreme natural events such as storms, avalanches and extreme snowfall.

Even the bark beetle, feared elsewhere in the aftermath of such natural events, has in our area led to a welcome transition of former commercial forests to nearer-natural biocoenoses.

\section{What is wilderness?}

There are various definitions of the term wilderness, including the conclusion that wilderness cannot be defined precisely. If you work with this term, however, you must have a concept of it and agree on a feasible definition for handling the everyday tasks of running a WA.

The ideal type of absolute virginity and consistent non-interference is almost impossible to realize in the

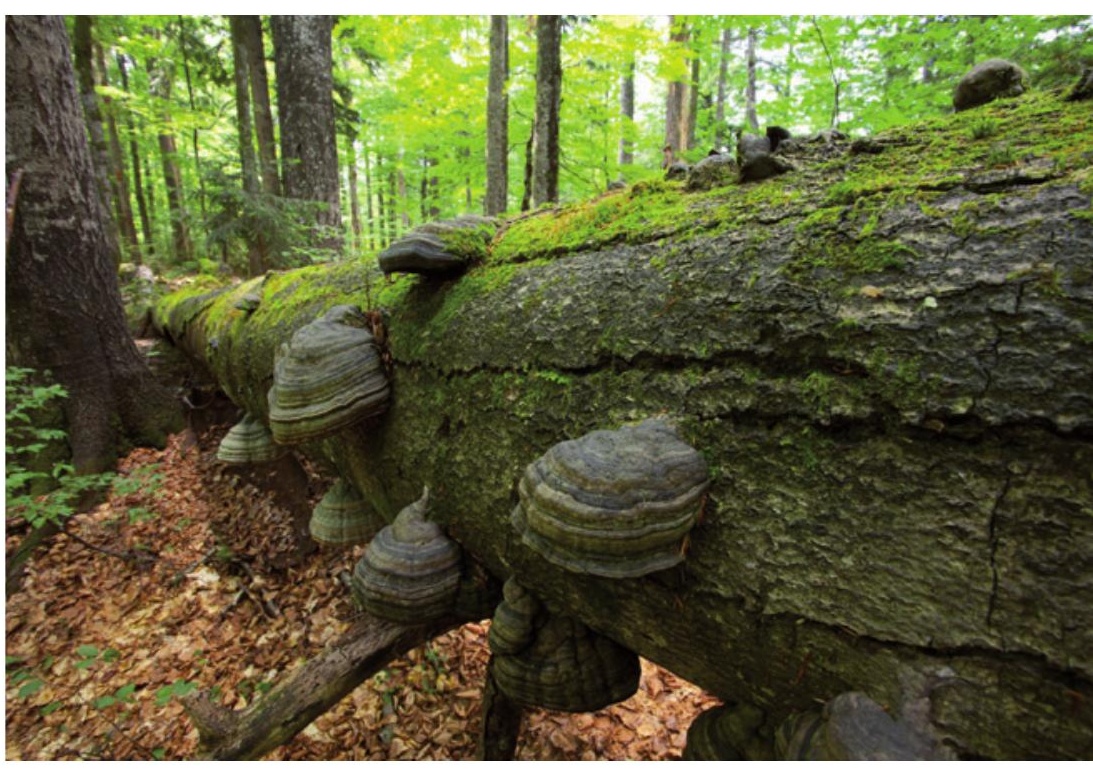

Dürrenstein Wilderness Area. C Hans Glader

crowded situation of densely populated Central Europe. Even if this were possible, the impacts of our civilization have reached all areas of our planet and are leaving measurable traces. If we take the pollutants and nutrients released by humans via atmospheric circulation or via the water cycle alone, we cannot talk of a wilderness completely devoid of human influence. Our objective therefore is to minimize human intervention as much as possible and letting natural processes take their course insofar as the legal and social framework permits. 
rounding land. Nor is wildlife management just concerned with wild animals, it also takes into account humans and their interaction with the environment. In addition to studying and monitoring wild animals, we also place a high priority on dealing with humans in and around the protected area.

Wildlife management also includes supporting measures such as feeding red deer in winter or feeding Ural owls during the settling-in period, plus resettlement or supporting measures to maintain stocks of certain species. A very controversial debate is currently going on about how to deal with invasive species, which have recently increased in our forests. Controlling hoofed game is another essential part of wildlife management. Below we shall give details of our approach.

Some species have been reduced so much that they hardly occur in Austria any more or have even died out altogether. Recolonization projects can make such species part of the natural indigenous fauna again. At a time when habitats are destroyed daily and disappear completely, sanctuary spaces for the maintenance of species and populations are becoming more essential by the day. Dürrenstein WA offers such an oasis in the midst of a cultural landscape shaped by man.

The protected area management of Dürrenstein WA, in cooperation with many partners, is carrying out the resettlement of the Ural owl which had been hunted to extinction in Austria around 100 years ago. The WA and Wienerwald Biosphere Reserve are the only two areas in Austria where Ural owls have been released into the wild since 2009 .

\section{Controlling hoofed game}

Ideally, in a wilderness area there should not be any intervention in the ecosystem at all, including no control of wild animals. In our case, all indigenous wildlife is left untouched except for hoofed game. The reason for this intervention is solely the intolerable impact of such game on vegetation and woodland rejuvenation. Necessary control is carried out by shooting but not in the form of traditional hunting as we do not aim to use the game for meat, as a trophy or for the hunting experience.

Unfortunately the small size of the protected area means that self-regulation cannot work because external influences from feeding and from traditional commercial hunts are simply too strong. All the same, we do not need to exert much control, as the sometimes very severe winters with large amounts of snow have a big impact on red deer, roe deer and chamois. In recent years, we have been able to leave roe deer and chamois to their own devices. The situation is different for red deer. They claim large areas and travel seasonally to feeding places outside the protected area. Hence we have to reduce their number and aim to do so mainly in the hunting grounds just outside the protected area. In the protected area itself, only very few animals are shot. For the wilderness, this represents

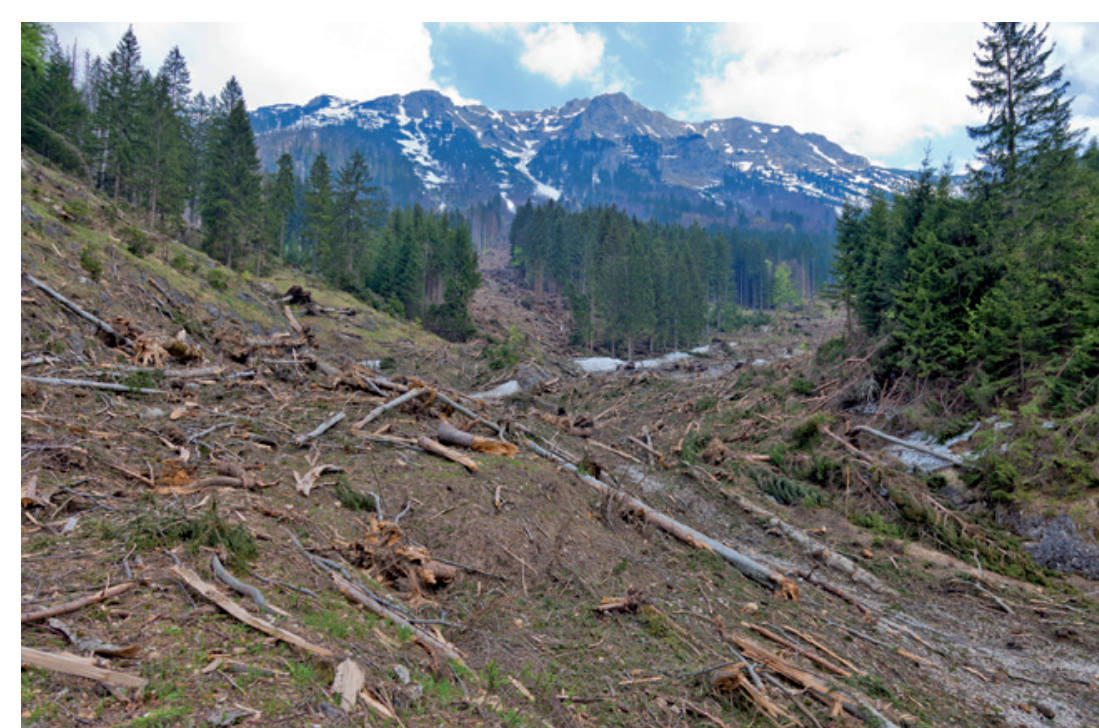

Avalanche effects in the Hundsau. (C) Theo Kust

a negligible intervention in the total ecology, given the great mobility of this species. Our aim would still be no intervention at all, but we need to respect the strong emotional investment in the hunting game in the region and the considerable impact of the red deer on the commercial forest adjacent to the wilderness area. The polarization between the interests of forestry, hunting traditions and misguided concepts of animal protection makes it difficult to deal with the issue in a way that does justice to forest ecology and game biology. On the issue of the return of large predators to Central Europe, the spectrum runs from biophilia to carniphobia, which makes it a particularly sensitive and challenging part of wildlife management. We see our role as that of mediator and for us large predators are part of the species spectrum. However, currently the role of bears, wolves and lynx in controlling hoofed game is negligible, even though these large predators are occasionally present in the region and in the protected area.

Much more important for self-regulation is the weather. In extreme years with large amounts of snow and long snow cover, we register high mortalities in winter. Even in spring, unfavourable weather weakens individuals and increases the mortality in young animals, dampens the breeding rate and thus reduces stocks, which we allow to happen. In this we differ sharply from the traditional hunts in the surrounding area. Our activities to control hoofed game are solely aimed at ensuring the rejuvenation of natural woodland and at protecting sensitive types of vegetation from overgrazing. As we do not use the forest commercially, we can tolerate higher stocks of game because we allow longer rejuvenation periods. In the protected area we do not need to achieve harvestable stands within 80 to 100 years. We do however need a rejuvenation of indigenous tree species and cannot tolerate permanent failure to rejuvenate the tree stands, which makes an occasional intervention in hoofed game stocks necessary. On the other hand, the wilderness area can tol- 


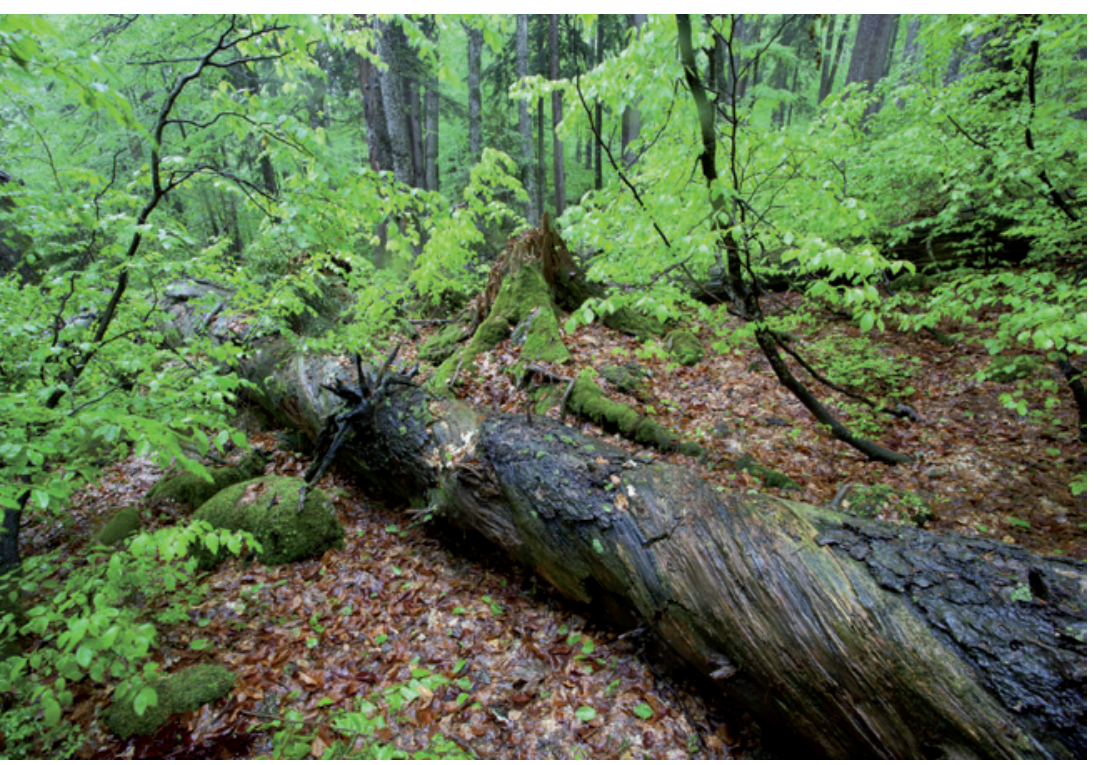

Dürrenstein Wilderness Area. (C) Hans Glader

erate much lower game stands than are called for in commercial hunts as we do not create revenue from hunting. Constant game stocks that guarantee the same number of kills (and with it a stable income) every year are not natural and therefore no objective for the wilderness area. We aim for great fluctuation in stocks, depending on weather and other environmental conditions such as illnesses and predators. Phases of low ruminating stocks will let the woodland recover and strengthen so that it can later cope with higher stocks of hoofed game.

\section{Visitor management}

In a wilderness area of IUCN Category I $(\mathrm{a}+\mathrm{b})$, visitor management is another key task for the protected area administration that requires sensitivity and empathy. In addition to exploring wildlife and ecological interdependencies, the wilderness area administration also aims to provide education, encouraging people to engage with the unique natural environment and to treat this environment in a responsible manner. Visitors are helped to understand the ecological complexity and the significance of wilderness and protected areas.

Only if we (and not just the wilderness area administration) succeed in sensitizing people in the longer term will future generations appreciate and protect these rare treasures. It is almost impossible to put a figure on the wealth of nature, but civilization includes values other than economic use that can ensure its survival. Once destroyed, ecosystems are lost forever.

Even just observing natural processes has an impact on them. In a system that is meant to remain free from human influence, educational activities are a delicate matter. However, we only respect and protect what we can perceive and understand. Hence, excursions into the wilderness area and its virgin forest are essential to teach us how wilderness may be conserved and / or allowed to resurface from a cultural landscape shaped by humans. By setting temporal and spatial limits for such excursions, we try to keep the impact within tolerable limits. Other influences, such as pollutants in the air, are beyond our sphere of action. Experience has shown that largely intact systems cope better with such pressures but even they bear the marks of such adverse effects.

Visitors are welcome in the wilderness area if they keep to the paths and respect the ban on utilization (including gathering mushrooms or berries). We want them to leave nothing nor to take anything with them except beautiful memories and photographs.

Main excursion targets are the virgin forest Rothwald, the ridge of the Wandeckrücken in Hundsau and the adjacent Leckermoor bog. In addition, we offer themed excursions in and around the WA, for instance on fauna, flora, butterflies, bats, large predators, geology, nature photography, nature \& culture and microorganisms under the microscope.

\section{Conclusion}

For wilderness to be preserved or allowed to reemerge, we need to allow natural processes to a quite radical degree. This means a departure from our purely anthropocentric view, which is not easy. Wildlife management is called upon to encourage an understanding for such an approach in the population and an enthusiasm for the idea of a wilderness in the political decision makers if we want to preserve these natural treasures for the future.

\section{Authors}

Mag. Ingrid Kohl

born 1982, grew up in the Vienna Woods, studied biology and ecology in Vienna and geo informatics in Salzburg. Since 2000 working as ornithologist, herpetologist and conservation expert in provincial government departments, universities and engineering firms, since 2009 scientist at the Dürrenstein WA.

\section{Reinhard Pekny}

born 1959, has worked as forestry expert, wildlife biologist, hunter and pond pisciculturist on several continents. Joined the staff of Dürrenstein WA in 1997, as ranger he is responsible for natural space management and education activities. His research interests are wilderness areas and freshwater decapods.

Protected Area Administration Dürrenstein Wilderness Area, Brandstatt 61, 3270 Scheibbs, Austria office@wildnisgebiet.at http://www.wildnisgebiet.at 